\title{
The ultra-fast Kelvin waves in the equatorial ionosphere: observations and modeling
}

\author{
A. N. Onohara, I. S. Batista, and H. Takahashi \\ Aeronomy Division, Instituto Nacional de Pesquisas Espaciais, São José dos Campos, Brazil \\ Correspondence to: A. N. Onohara (amelia@laser.inpe.br)
}

Received: 19 June 2012 - Revised: 15 November 2012 - Accepted: 14 January 2013 - Published: 7 February 2013

\begin{abstract}
The main purpose of this study is to investigate the vertical coupling between the mesosphere and lower thermosphere (MLT) region and the ionosphere through ultra-fast Kelvin (UFK) waves in the equatorial atmosphere. The effect of UFK waves on the ionospheric parameters was estimated using an ionospheric model which calculates electrostatic potential in the E-region and solves coupled electrodynamics of the equatorial ionosphere in the E- and F-regions. The UFK wave was observed in the South American equatorial region during February-March 2005. The MLT wind data obtained by meteor radar at São João do Cariri $\left(7.5^{\circ} \mathrm{S}\right.$, $\left.37.5^{\circ} \mathrm{W}\right)$ and ionospheric F-layer bottom height $\left(h^{\prime} \mathrm{F}\right)$ observed by ionosonde at Fortaleza $\left(3.9^{\circ} \mathrm{S} ; 38.4^{\circ} \mathrm{W}\right)$ were used in order to calculate the wave characteristics and amplitude of oscillation. The simulation results showed that the combined electrodynamical effect of tides and UFK waves in the MLT region could explain the oscillations observed in the ionospheric parameters.
\end{abstract}

Keywords. Ionosphere (Equatorial ionosphere; Ionosphereatmosphere interactions) - Meteorology and atmospheric dynamics (Waves and tides)

\section{Introduction}

In the equatorial atmosphere, where the Coriolis force is insignificant, the Kelvin waves, as well as Rossby-gravity waves modes become important (Holton, 1992). Kelvin waves are due to the change in the Coriolis parameter near the equator and are considered to be a special kind of gravity wave modified by the Earth's rotation (Andrews et al., 1987). These waves are trapped in the equatorial region inducing perturbations in the zonal wind velocity, temperature and geopotential fields, and the phase propagates eastwards.
It is believed that they are excited by tropical convection systems (Holton, 1972; Salby and Garcia, 1987; Bergman and Salby, 1994; Pancheva et al., 2008).

The UFK wave effects in the mesosphere were first discussed by Forbes (2000) in the GSWM (global scale wave model). He indicated that a UFK wave with a period of about 3 days and zonal wavenumber 1 , can reach the lower thermosphere with amplitudes of $10-25 \mathrm{~K}$ in the temperature field, and variations of $10-40 \mathrm{~m} \mathrm{~s}^{-1}$ in the zonal wind field. Moreover, the model predicted a possibility for the wave to reach higher altitudes.

In relation to the presence of UFK waves in the ionosphere, several mechanisms have been proposed to explain the propagation of these waves from the MLT region to the ionosphere. One of them is through the ionospheric dynamo effects. It is known that the neutral wind responsible for the ionospheric dynamo is modulated mainly by tides, and also by other dynamical effects such as planetary waves. These neutral wind components between $100-170 \mathrm{~km}$ altitude have enough magnitude to create electric fields which could modulate the peak height and plasma density of the ionospheric $\mathrm{F}$ layer.

In the Brazilian equatorial region, Takahashi et al. (2005, 2006, 2007, 2009) pointed out the occurrence of UFK wave oscillations in both MLT and ionosphere observations. Takahashi et al. (2007) applied wavelet analysis to meteor radar wind data from São João do Cariri $\left(7.4^{\circ} \mathrm{S}, 36.5^{\circ} \mathrm{W}\right)$, ionospheric parameters $h^{\prime} \mathrm{F}$ (minimum $\mathrm{F}$ layer virtual height) and $f o \mathrm{~F} 2$ (F layer critical frequency) measured by a digissonde installed at Fortaleza $\left(3.9^{\circ} \mathrm{S}, 38.4^{\circ} \mathrm{W}\right)$, and temperature data from the TIMED/SABER satellite in order to investigate UFK wave oscillations in both mesospheric and ionospheric parameters. This was the first report of a clear evidence of propagation of a UFK wave from the stratosphere 
to the ionosphere. From the characteristics of the downward phase propagation (wavelength $\sim 40 \mathrm{~km}$ ), longitudinal and latitudinal extension, the authors concluded that the oscillation was compatible with a 3.5-day Ultra Fast Kelvin wave. In a subsequent work, Takahashi et al. (2009) investigated the day-to-day variability of the F2 layer evening uplift which controls the spread $\mathrm{F}$ onset time. The results also revealed UFK wave modulations, reinforcing the importance of this kind of wave in the coupling between the neutral and ionized atmosphere.

Coupling mechanisms between the neutral atmosphere and ionosphere by wave propagations have recently been studied by modeling. Liu et al. (2010) used the NCAR thermosphere-ionosphere-mesosphere electrodynamics general circulation model (TIME-GCM) to demonstrate that the presence of a quasi-stationary planetary wave could generate large ionospheric changes, including changes in the dynamo electric field/ion drift, F2 peak height and electron density, and TEC (total electron content) for solar minimum conditions. Using the same model, Chang et al. (2010) investigated the effect of an UFK wave on the thermosphere and ionosphere. They found that UFK waves with amplitudes of approximately $20-40 \mathrm{~m} \mathrm{~s}^{-1}$ in zonal wind fields and $10-20 \mathrm{~K}$ in temperature fields in the MLT region could result in approximately $8-12 \%$ of neutral density perturbations at $350 \mathrm{~km}$ of altitude. They also found perturbation of $25-50 \%$ in the TEC in the region of the equatorial ionization anomaly. Miyoshi et al. (2011) studied the generation mechanism of the equatorial mass density anomaly (EMA) in the equatorial upper atmosphere using the ground-to-topside model of the Atmosphere and Ionosphere for Aeronomy (GAIA). The results showed that the daytime EMA is caused by the in situ diurnal tide and the upward propagating terdiurnal tide from the lower atmosphere. This is the first report concerning the importance of upward propagating tides in the EMA formation.

Takahashi et al. (2006) highlighted that the possible influence of Kelvin waves in the equatorial ionosphere would be through the interaction of the wave with the winds generating the E- and F-region dynamos. Miyoshi and Fujiwara (2006) demonstrated in their general circulation model that the UFK wave could propagate upward to the lower thermosphere. Chang et al. (2010) showed that the effects of a UFK wave can be transmitted to the thermosphere by wind dynamo modulation and direct vertical wave propagation, affecting the thermosphere neutral densities at $350 \mathrm{~km}$ and the total electron content.

In the present study, we use a numerical model that takes into account the electrodynamical coupling between the lowlatitude E-region and the equatorial F-region (Batista et al., 1986; Carrasco et al., 2007) in order to explain the vertical drift of F-layer observed by Takahashi et al. (2007, 2009). The low latitude quiet-time ionospheric electric fields and plasma drifts are driven by the dynamo action of E- and Fregion thermospheric neutral winds. The major sources of thermospheric winds are atmospheric tides driven by the absortion of solar ultraviolet radiation in the thermosphere and heating in the troposphere and stratosphere (Fejer, 2011). The atmospheric tides are global-scale waves with periods of $24 \mathrm{~h}$ and the harmonics of a day.

Other waves from tropospheric origins like planetary and gravity waves also play an important role in ionospheric variability. These waves can propagate upwards carrying momentum and energy to higher altitudes modifying the atmospheric structure of that region. In the present work we included UFK wave induced wind oscillations observed in the MLT region as an input to the model. The results are compared with the F-layer vertical drift observed at Fortaleza during the UFK event, from 1 to 11 March 2005, which has been observed by Takahashi et al. (2007).

\section{Methodology}

The vertical drift model developed by Batista et al. (1986) (hereafter referred as CODB) is a theoretical model used to simulate the electrodynamic coupling process between $\mathrm{E}$ and $\mathrm{F}$ ionospheric regions, based on the model developed by Heelis et al. (1974). In the model the coordinate directions (up, magnetic south, magnetic east) are denoted by the spherical polar coordinates $(r, \theta, \varphi)$. The vertical $V_{\text {in }}$ and zonal $V_{\mathrm{i} \varphi}$ ionospheric plasma drifts can be calculated using the following equations:

$$
\begin{aligned}
& {\left[1+\left(\frac{v}{\omega}\right)^{2}\right] V_{\text {in }}=\frac{v}{\omega} U_{\varphi}+\frac{v}{\omega} \frac{E_{\mathrm{n}}}{B}+\frac{E_{\varphi}}{B},} \\
& {\left[1+\left(\frac{v}{\omega}\right)^{2}\right] V_{\mathrm{i} \varphi}=\left(\frac{v}{\omega}\right)^{2} U_{\varphi}+\frac{v}{\omega} \frac{E_{\varphi}}{B}-\frac{E_{\mathrm{n}}}{B},}
\end{aligned}
$$

where $v$ is the collision frequency between the ions and neutrals, $\omega$ is the ion gyrofrequency, $B$ is the geomagnetic field, $E_{\mathrm{n}}$ and $E_{\varphi}$ are the electric fields in the vertical and zonal directions, respectively, and $U_{\varphi}$ is the thermospheric zonal wind calculated from a nonlinear partial differential equation.

The total electric field of the $\mathrm{E}$ region can be expressed as $\boldsymbol{E}_{\mathrm{t}}=\boldsymbol{E}^{*}+\boldsymbol{U}^{\mathrm{E}} \times \boldsymbol{B}$, where $\boldsymbol{E}^{*}$ is the electrostatic field, and $\boldsymbol{U}^{\mathrm{E}}$ is the tidal wind velocity at the E-region $(\sim 120 \mathrm{~km}$ of altitude). The tidal wind velocity used in this work is the same one used in the previous works by Heelis et al. (1974) and Batista et al. (1986) for the evanescent diurnal mode $(1,-2)$ (Tarpley, 1970). The reason for using only this mode is that this is the main mode responsible for the generation of the solar quiet (Sq) ionospheric currents and electric fields. It is known that other tidal modes give their contribution to the Sq currents and electric fields, but the vertical drifts resulting from these modes, without the inclusion of F-region dynamo, could not simulate the pre-reversal peak. As there is no influence from other tidal modes on the vertical drift F-region 
pre-reversal peak results in this study, we considered only the $(1,-2)$ mode. We assume that $\boldsymbol{U}^{\mathrm{E}}$ has no vertical component and that $\boldsymbol{E}^{*}$ can be expressed in the form:

$\boldsymbol{E}^{*}=-\nabla \Psi$,

where $\Psi$ is a 2 nd order partial differential equation of the E-region electrostatic potential. Knowing $\Psi$, the E-region polarization electric fields, mapped to the F-region through magnetic field lines are given by

$$
E_{\mathrm{n}}=\frac{\Delta \sin ^{3} \theta^{*}}{r^{*} \Delta^{*} \sin I^{*} \sin ^{3} \theta}\left(\frac{\partial \Psi}{\partial \theta}\right)^{*}
$$

$E_{\varphi}=-\frac{1}{r^{*} \sin \theta}\left(\frac{\partial \Psi}{\partial \varphi}\right)^{*}$,

where $I^{*}$ is the magnetic inclination angle in the limit between the E- and F-regions. The asterisks denote that values are taken at the point where the field line enters into the Eregion. The solutions of Eqs. (4) and (5) are used to calculate the ionospheric plasma drifts in the Eqs. (1) and (2), and the thermospheric zonal wind. Details about the equations can be found in the study of Heelis et al. (1974) and Batista et al. (1986).

The E-region polarization electric fields (Eqs. 4 and 5), mapped to the F-region through magnetic field lines, are responsible for controlling the plasma drifts and currents in this region, mainly during the daytime. During the local evening in the equatorial ionosphere, the F-layer undergoes rapid uplift. Also thermospheric zonal winds change direction from westward during the daytime to eastward in the evening sector. According to the model from Farley et al. (1986) for the pre-reversal enhancement, near the sunset terminator the Fregion dynamo electric field $E_{\mathrm{z}}$ is no longer shorted out and approaches $-\boldsymbol{U} \times \boldsymbol{B}$ (where $\boldsymbol{U}$ is thermospheric wind and $\boldsymbol{B}$ is the magnetic field). This field maps to an equatorward electric field in the E-layer and drives a westward Hall current. But if no current flows in the nightside E-region, a negative polarization charge must develop at the terminator, with polarization electric fields $E_{\mathrm{y}}$ (in the zonal direction). This $E_{\mathrm{y}}$ maps back to the F-region and causes an upward $\boldsymbol{E} \times \boldsymbol{B}$ plasma drift in the dayside and later a downward drift in the nightside. The vertical plasma transport is a very important component in the formation and structuring of the ionization layers. A wide range of variability can be seen in the ionosphere. They can arise from magnetosphere-ionosphere coupling processes or from vertical coupling of atmospheric and ionospheric regions through atmospheric waves (Abdu et al., 2006), including the UFK wave.

According to Takahashi et al. (2009), the UFK waves can play an important role over the equatorial ionosphere through dynamo effects. The zonal wind in the lower thermosphere could be one of the principal causes of the day-to-day variability in $h^{\prime}$ F. The UFK waves can superimpose onto, and/or modulate the tidal winds (mainly the zonal component), resulting in an electron density variation of the E-layer by the E-region dynamo. If the UFK waves reach more elevated altitudes (between 150 to $200 \mathrm{~km}$ ), they can modulate the thermospheric zonal wind velocity directly, resulting in a direct modulation of the $\boldsymbol{E} \times \boldsymbol{B}$ drift in the F-layer too, thus affecting the F-region dynamo. In the present work we studied the UFK wave effects over the ionosphere by the E-F layer coupling model (considering the E-layer dynamo field is mapping to F-layer, consequently inducing the F-layer uplift). The mechanism associated with direct propagation of an UFK wave into the F-region was not considered, since we have no estimation of UFK wave amplitude in these altitudes.

Our analysis consisted primarily in obtaining the UFK wind amplitudes at $120 \mathrm{~km}$, which will be superposed to the tidal winds present in the model. As we do not have wind observations around this altitude due to instrumental limitation, we developed a methodology to calculate the UFK amplitudes from observed meteor wind data taken at MLT altitudes. The details of the process will be given bellow.

The mesospheric neutral wind observations by meteor radar were taken between 80 and $100 \mathrm{~km}$ altitude over different equatorial stations as shown by Takahashi et al. (2007). During the period from 1 to 11 March 2005 (days 60-70), wavelet spectral analyses of both the mesospheric and ionospheric temporal series showed simultaneous oscillations compatible with those caused by UFK waves. Amplitude and phase analysis performed over the UFK zonal wind components showed that this wave had a vertical wavelength of around $40 \mathrm{~km}$ and phase velocity of $120 \mathrm{~m} \mathrm{~s}^{-1}$, in agreement with theoretical prediction of the UFK waves.

Once the vertical wavelength is known, it is possible to calculate the UFK wave component at $120 \mathrm{~km}$. The expression $y(z, t)=A(t) \cos (m z-\varphi) \exp (z / 2 H)$ was used to estimate the vertical wind profile at each time $t$ and altitude $z$. $H$ is the scale height, $m=2 \pi / \lambda_{z}$ is the vertical wavenumber, and $\lambda_{\mathrm{z}}=40 \mathrm{~km}$ was obtained from observation. The amplitude $A(t)$ and the phase difference $\varphi$ were obtained from least squares analysis made over each vertical zonal wind profile from observed UFK zonal wind components. The exponential factor present in the equation represents the amplitude wave growth with altitude. These calculations were made assuming that the UFK waves propagate vertically (if a wave propagates upwards without attenuation its amplitude grows exponentially as the atmospheric density decreases with the altitude). This approximation is necessary in this present study because we do not know the UFK wave amplitudes at the E-region dynamo altitudes. In the TIMED/SABER temperature UFK oscillations, Takahashi et al. (2009) found an amplitude of $5 \mathrm{~K}$ at $80 \mathrm{~km}$, and an amplitude of $10 \mathrm{~K}$ at $120 \mathrm{~km}$. This indicates that the wave amplitude increased with height by a factor of 2 from the $40 \mathrm{~km}$ height range. 


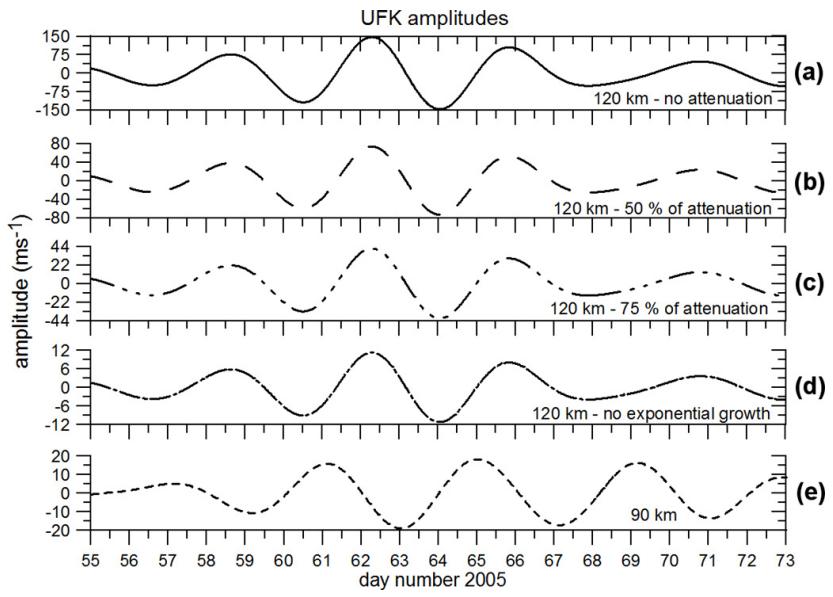

Fig. 1. UFK zonal winds amplitudes at $120 \mathrm{~km}$. Three different cases for the vertical propagation function were considered: (a) no attenuation, (b) $50 \%$ of attenuation, (c) $75 \%$ of attenuation and (d) without exponential growth. Panel (e) shows the UFK zonal wind at $90 \mathrm{~km}$ measured over São João do Cariri.

\section{Results}

In order to test the influence of different wind amplitude on the F-layer vertical drifts, we considered four different conditions for the upward propagating wave: (1) exponential growth of the wave amplitude from 90 to $120 \mathrm{~km}$ altitude, (2) a $50 \%$ attenuation applied to the exponential growth factor, (3) a $75 \%$ attenuation applied to the exponential growth factor, and (4) no exponential growth but a constant amplitude with height. The results at $120 \mathrm{~km}$ are shown in Fig. 1 (panels a, b, c and d) together with the UFK zonal wind amplitudes observed at $90 \mathrm{~km}$ at São João do Cariri (Fig. 1e). The values at $120 \mathrm{~km}$ will be used as input parameters in the CODB model. It is possible to see that the main difference between the four amplitudes at $120 \mathrm{~km}$ is their magnitudes. The higher values $\left(\sim 150 \mathrm{~m} \mathrm{~s}^{-1}\right.$, Fig. 1a) are related to the propagation with no attenuation in the exponential growth factor; for the $50 \%$ attenuation case (Fig. 1b), the higher values were approximately $80 \mathrm{~m} \mathrm{~s}^{-1}$. For the $75 \%$ attenuation case (Fig. 1c), the UFK temporal variations are between $\pm 44 \mathrm{~m} \mathrm{~s}^{-1}$. The smallest values are associated with the propagation without exponential growth with altitude $\left(\sim 12 \mathrm{~m} \mathrm{~s}^{-1}\right.$, Fig. 1d). It should be noted that for this case, the amplitude at $120 \mathrm{~km}$ is smaller than those observed at $90 \mathrm{~km}\left(\sim 20 \mathrm{~m} \mathrm{~s}^{-1}\right.$, Fig. 1e), because of the phase difference in vertical variation of the UFK wave amplitude. The results shown in Fig. 1 were used as input to CODB to calculate the new vertical drifts in the model.

Figure 2 shows the F-layer vertical drift velocity at $300 \mathrm{~km}$ altitude calculated using CODB model, considering a UFK wave propagating with no attenuation, and the corresponding wavelet power spectrum. The CODB model originally considers that the E-region dynamo is generated by the action

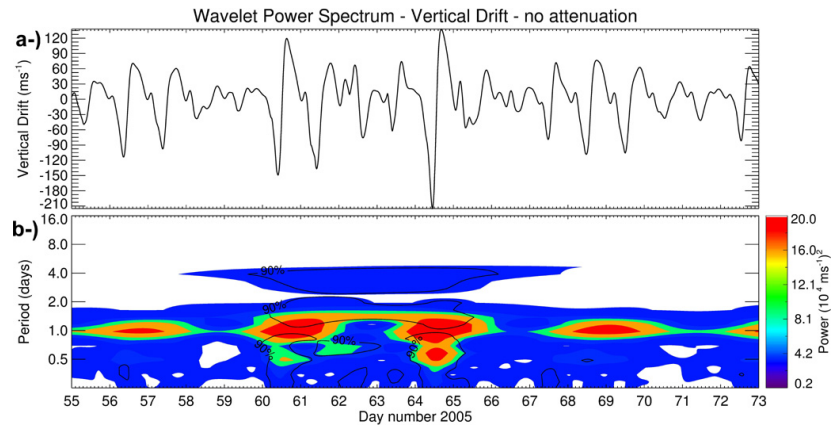

Fig. 2. (a) vertical drifts calculated by the CODB model considering the case where the UFK wave propagated upwards without attenuation. (b) wavelet power spectrum.

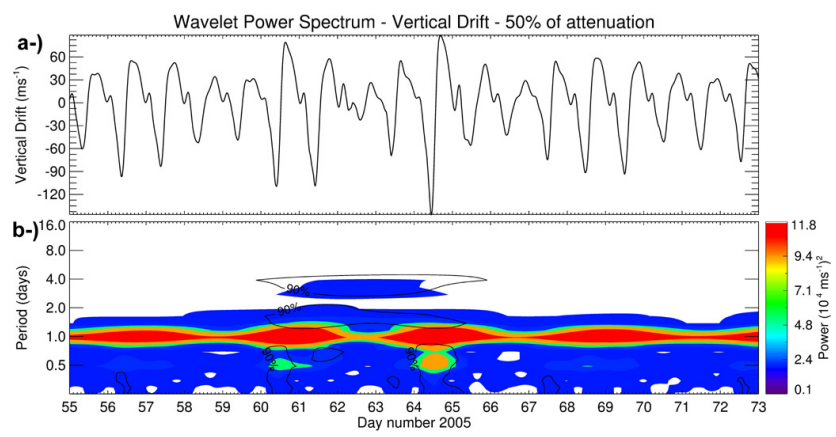

Fig. 3. (a) vertical drift calculated for the case where the UFK wave propagated upwards with $50 \%$ attenuation. (b) wavelet power spectrum.

of tidal winds. For all of the propagation cases discussed in this study, the UFK wave is superposed on the tidal winds in generation of the ionospheric electric fields. The tidal winds amplitude used in the model was around $20 \mathrm{~m} \mathrm{~s}^{-1}$ at $120 \mathrm{~km}$ altitude. Figure 2a shows the temporal variation of the amplitude of vertical plasma drift velocity calculated by the model. The vertical drift velocity varied from -200 to $+120 \mathrm{~m} \mathrm{~s}^{-1}$ during the period of days $60-66$. Figure $2 b$ shows the wavelet spectrum of the vertical drift velocities. It is possible to see an amplitude increase of the drift velocity (acceleration and deceleration) between the days 60-67 (1 to 8 March). In addition to the 3.5 day oscillation feature, it is interesting to note that there is a modulation of the diurnal component and an additional semidiurnal tidal component.

Figure 3 shows the case of $50 \%$ attenuation of the wind growth in the CODB model, and the corresponding wavelet power spectrum. Figure 3a shows the daily variation of vertical drifts, and their minimum and maximum values were around -150 and $90 \mathrm{~m} \mathrm{~s}^{-1}$, respectively. Figure $3 \mathrm{~b}$ shows a similar behavior to that seen in Fig. 2b. In Fig. $3 b$ it is possible to see a significant 3.5 day oscillation feature between the days 60-66, in addition to the tidal oscillation over the entire time interval. Some semidiurnal tidal modulations can also 


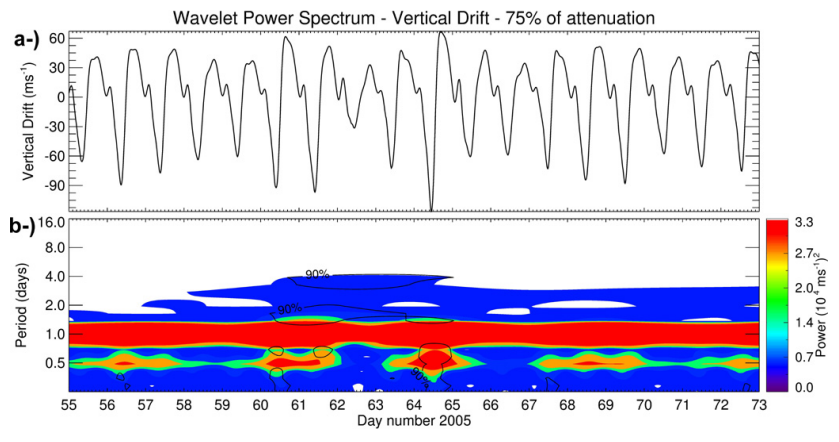

Fig. 4. (a) vertical drift calculated for the case where the UFK wave propagated upwards with $75 \%$ attenuation. (b) wavelet power spectrum.

be observed in the time interval where the 3.5 day oscillation signature is present.

Figure 4 shows the CODB model results for the case of $75 \%$ of attenuation. Figure $4 \mathrm{a}$ shows the vertical drifts daily variations from day 55 to 73 ; these variations were around -115 and $65 \mathrm{~m} \mathrm{~s}^{-1}$. Figure $4 \mathrm{~b}$ shows the vertical drift wavelet power spectrum. As seen in Figs. $2 \mathrm{~b}$ and $3 \mathrm{~b}$, a clear UFK oscillation is present between the days 60-66. It is possible to see modulation of diurnal and semidiurnal tidal oscillations and a two-day wave oscillation, too. The diurnal tidal modulations seem to be weaker in comparison with the wavelet spectrum of Figs. $2 b$ and $3 b$. Analyzing Fig. 4, it is possible to confirm that an UFK zonal wind amplitude at $120 \mathrm{~km}$, with maximum amplitudes around $44 \mathrm{~m} \mathrm{~s}^{-1}$ (as shown in Fig. 1c), can modulate the F-layer vertical uplifting.

Figure 5 presents the vertical drift results calculated for the case (4) no exponential growth in the CODB model and corresponding wavelet power spectrum. The effect of 3.5 day oscillation is very small, which is different to what was seen in Figs. 2b, 3b and 4b. No significant modulation of the diurnal tides can be seen. Figure 5a shows the vertical drift results for this case. The minimum and maximum variations were around -100 and $60 \mathrm{~m} \mathrm{~s}^{-1}$, respectively.

\section{Discussion}

From Figs. 2, 3, 4 and 5, we understand that the effects of UFK waves on the ionospheric vertical drifts are prominent when the zonal wind amplitude at $120 \mathrm{~km}$ is larger than $40 \mathrm{~m} \mathrm{~s}^{-1}$. In all the cases considered is this work the amplitude of wavelet spectrum is smaller for the UFK wave in comparison with the tidal waves. However the significance level of the wavelet spectrum for the UFK wave oscillations is beyond $90 \%$. In the present study it was also possible to verify that the superposition of UFK and tidal waves in the generation of the ionospheric E-region dynamo is capable of modulating the diurnal tide as well as generating semidiurnal tides and, further, two day wave signatures in iono-

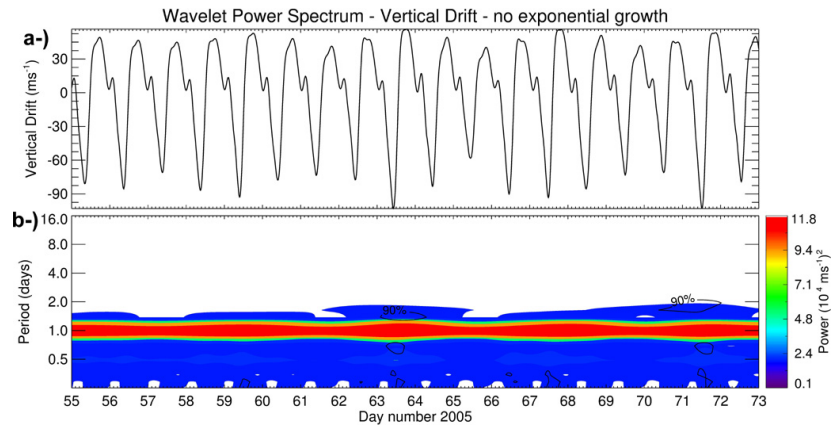

Fig. 5. (a) vertical drifts calculated by the CODB model considering the case where the UFK wave propagated upwards with no exponential growth of amplitude. (b) wavelet power spectrum.

spheric vertical drift. This could be an indicator of a nonlinear interaction between the UFK waves and tidal waves, as pointed out by Teitelbaum and Vial (1991). They showed that the nonlinear interactions between tides and planetary waves could generate two secondary waves (or child waves) of which frequencies are the sum and difference of frequencies of the primary waves. The nonlinear interaction between the UFK wave and the diurnal and semidiurnal waves can generate child waves with periods of 1.4 and 1.71 days, respectively. Although this study considers only the superposition of the UFK to the tidal waves at $120 \mathrm{~km}$ altitude the nonlinear interaction could still occur through the electrodynamical processes.

England et al. (2012) reported evidence of a nonlinear interaction between the UFK wave and the diurnal tides using the ground-based meteor radar at Thumba $\left(8.5^{\circ} \mathrm{N}, 77^{\circ} \mathrm{E}\right)$ and the incoherent scatter radar at Arecibo $\left(18^{\circ} \mathrm{N}, 66^{\circ} \mathrm{W}\right)$. The nonlinear interaction appeared to happen in altitudes from 82 to $88 \mathrm{~km}$. The child waves produced by the interaction could propagate upward to approximately $150 \mathrm{~km}$ altitude through the altitude range of the E-region ionosphere $(110 \mathrm{~km})$. It might be possible that the UFK wave indirectly impacts the ionosphere through this mechanism. A subsequent study by Liu et al. (2012) observed this same 3-day wave signature in the top side of ionosphere at mid-latitude, and suggested that the UFK wave oscillations were transmitted through modulations of the ionospheric dynamo in the lower latitudes.

In order to compare the model calculation with observations, the maximum vertical drift velocities observed at Fortaleza during the period from 27 February to 9 March 2005 (days 58-68) are shown in Fig. 6, together with the model results. The maximum vertical drift velocities were obtained from the vertical drift displacement of the F-layer minimum vertical height $\left(h^{\prime} \mathrm{F}\right)$ during the evening pre-reversal enhancement. The observed values (blue lines) were obtained from the $h^{\prime} \mathrm{F}$ evolutions during the evening pre-reversal uplifting. The four cases with different UFK wave amplitude at $120 \mathrm{~km}$ altitude are represented by the green (exponential growth), 


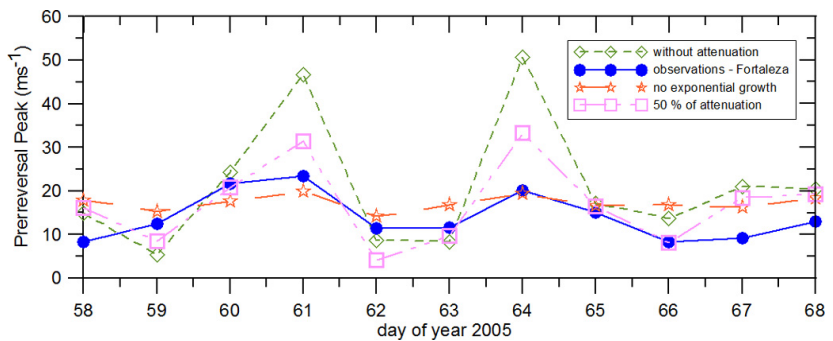

Fig. 6. Maximum vertical drift velocity calculated during the evening pre-reversal enhancement hours. The blue line represents the observational results. The green, pink and orange lines represent the results obtained by the model considering propagation with exponential growth of the wave amplitude, $50 \%$ attenuation, $75 \%$ attenuation and no exponential growth of the amplitude, respectively.

pink (50\% of attenuation), brown ( $75 \%$ of attenuation) and orange lines (no growth), respectively. We can notice that there are very similar behaviors between the model and observed values. For the case when the wave propagated without attenuation, the pre-reversal drift velocity varied from around $5 \mathrm{~m} \mathrm{~s}^{-1}$ (day 59) and $50 \mathrm{~m} \mathrm{~s}^{-1}$ (day 64). For the case of $50 \%$ attenuation, the variation was $\sim 3$ to $35 \mathrm{~m} \mathrm{~s}^{-1}$. Considering no exponential growth during upwards propagation, the pre-reversal drift velocities were around $15-20 \mathrm{~m} \mathrm{~s}^{-1}$. It is important to note in Fig. 6 that the best agreement between the observed and the modeled results is obtained when we considered $75 \%$ of attenuation (or $25 \%$ growth). The agreement is particularly good during the days 59-66. In this way we can confirm that a UFK zonal wind at $120 \mathrm{~km}$ with amplitude between $\pm 44 \mathrm{~m} \mathrm{~s}^{-1}$ is capable of modifying the ionospheric structure by modulation of the E-region dynamo effects.

In the present study the direct effect of the UFK waves over the F-layer dynamo was not considered due to a lack of information of the F-region neutral wind modulation. However, recently, Chang et al. (2010) reported that the UFK wave could continue to extend upwards into the thermosphere, even after their rapid decay above $\sim 150 \mathrm{~km}$ due to increasing dissipation. They further mentioned that the UFK waves still had small amplitudes at around $300 \mathrm{~km}$ which were capable of modulating the neutral density and the total ionosphere content. Therefore, the F-region dynamo effect caused by the UFK wind modulation cannot be ruled out. Neutral wind observations at F-region altitudes are necessary for further investigation.

The present CODB model can be applied to the other periodic oscillations present in the mesospheric neutral wind observations, such as the 2-day planetary wave. As a next step we plan to test different planetary wave periods in order to compare the effects of these waves over the equatorial ionosphere.

\section{Conclusion}

In the present work we estimated the variation of the evening pre-reversal enhancement (vertical drift) during UFK wave passage in the MLT region. Based on the observed zonal wind velocity between 80 and $100 \mathrm{~km}$ altitude, the wind velocity at $120 \mathrm{~km}$ was estimated and applied in the E-Fregion ionosphere coupling model (CODB). The results indicate that an additional zonal wind with amplitude larger than $40 \mathrm{~m} \mathrm{~s}^{-1}$ superimposed over the diurnal tides is sufficient to modulate F-layer uplifting consistent with that observed during the UFK event. In addition to this electrodynamical effect, modulation of the diurnal tides by the UFK wave could generate either semidiurnal tidal oscillations or 2-day oscillations in the F-layer vertical drift.

Acknowledgements. We would like to thank the anonymous referees for their helpful suggestions, and Alexander José Carrasco for his assistance with the computer code. The present work was partially supported by the Conselho Nacional de Desenvolvimento Científico e Tecnológico - $\mathrm{CNPq}$, and the Fundação de Apoio à Pesquisa do Estado de São Paulo - FAPESP, under the contract number 2011/11071-0.

Topical Editor K. Kauristie thanks two anonymous referees for their help in evaluating this paper.

\section{References}

Abdu, M. A., Ramkumar, T. K., Batista, I. S., Brum, C. G. M., Takahashi, H., Reinisch, B. W., and Sobral, J. H. A.: Planetary wave signature in the equatorial atmosphere-ionosphere system, and mesosphere E- and F-region coupling, J. Atmos. Sol-Terr. Phys., 68, 509-522, 2006.

Andrews, D. G., Holton, J. R., and Leovy, C. B.: Middle Atmospheric Dynamics. Academic Press, pp. 489, 1987.

Batista, I. S., Abdu, M. A., and Bittencourt, J. A.: Equatorial F region vertical plasma drifts: seasonal and longitudinal asymetries in the american sector, J. Geophys. Res., 91, 12055-12064, 1986.

Bergman, J. W. and Salby, M. L.: Equatorial wave activity derived from fluctuations in observed convection, J. Atmos. Sci., 51, 3791-3806, 1994.

Carrasco, A. J., Batista, I. S., and Abdu, M. A.: Simulation of the sporadic E layer response to prereversal associated evening vertical electric field enhancement near dip equator, J. Geophys. Res., 112, A06324, doi:10.1029/2006JA012143, 2007.

Chang, L. C., Palo, S., Liu, H., Fang, T., Liu, H., and Lin, C. S.: Response of the thermosphere to an ultra-fast Kelvin wave. J. Geophys. Res., 115, A00G04, doi:10.1029/2010JA015453, 2010.

England, S. L., Liu, G., Zhou, Q., Immel, T. J., Kumar, K. K., and Ramkumar, G. On the signature of the quasi3-day wave in the thermosphere during the January 2010 URSI World Day Campaign, J. Geophys. Res., 117, A06304, doi:10.1029/2012JA017588, 2012.

Farley, D., Bonelli, E., Fejer, B., and Larsen, M.: The Prereversal Enhancement of the Zonal Electric Field in the Equatorial Ionosphere, J. Geophys. Res., 91, A12, 13723-13728, doi:10.1029/JA091iA12p13723, 1986. 
Fejer, B. G.: Low Latitude Ionospheric Electrodynamics. Space Sci. Rev., 158, 145-166, doi:10.1007/s11214-010-9690-7, 2011.

Forbes, J. M.: Wave coupling between the lower and upper atmosphere: case study of an ultra-fast Kelvin wave, J. Atmos. SolTerr. Phys., 62, 1603-1621, 2000.

Heelis, R. A., Kendall, P. C., Moffet, R. J., Windle, D. W., and Rishbeth, H.: Electrical coupling of the $\mathrm{E}$ and $\mathrm{F}$ regions and its effects on F region drifts and winds, Planet. Space Sci., 22, 743-756, 1974.

Holton, H. R.: Waves in the equatorial stratosphere generated by tropospheric heat sources, J. Atmos. Sci., 29, 368-375, 1972.

Holton, J. R.: An Introduction to Dynamic Meteorology, Third Edition. Academic Press, San Diego, pp. 551, 1992.

Liu, H., Wang, W., Richmond, A. D., and Roble, R. G.: Ionospheric variability due to planetary waves and tides for solar minimum conditions, J. Geophys. Res., 115, A00G01, doi:10.1029/2009JA015188, 2010.

Liu, G., England, S. L., Immel, T. J., Kumar, K. K., Ramkumar, G., and Goncharenko, L.: Signatures of the 3-day wave in the low-latitude and midlatitude ionosphere during the January 2010 URSI World Day campaign, J. Geophys. Res., 117, A06305, doi:10.1029/2012JA017588, 2012.

Miyoshi, Y. and Fujiwara, H.: Excitation mechanism of intraseasonal oscillation in the equatorial mesophere and lower thermosphere, J. Geophys. Res., 111, D14108, doi:10.1029/2005JD006993, 2006.

Miyoshi, Y., Fujiwara, H., Jin, H., Shinagawa, H., Liu, H., and Terada, K.: Model study on the formation of equatorial mass density anomaly in the thermosphere, J. Geophys. Res., 116, A05322, doi:10.1029/2010JA016315, 2011.

Pancheva, D. V., Mukhtarov, P. J., Mitchell, N. J., Fritts, D. C., Ruggin, D. M., Takahashi, H., Batista, P. P., Clemesha, B. R., Gurubaran, S., and Ramkumar, G.: Planetary wave coupling (56-day waves) in the low-latitude atmosphere-ionosphere system, J. Atmos. Sol-Terr. Phys., 70, 101-122, 2008.
Salby, M. L. and Garcia, R. R.: Vacillations Induced by Interference of Stationary and Traveling Planetary Waves, J. Atmos. Sci., 44, 2679-2711, 1987.

Takahashi, H., Lima, L. M., Wrasse, C. M., Abdu, M. A., Batista, I. S., Gobbi, D., Buriti, R. A., and Batista, P. P.: Evidence on 2-4 day oscillations of the equatorial ionosfere $h^{\prime} \mathrm{F}$ and mesospheric airglow emissions, Geophys. Res. Lett., 32, 12, doi:10.1029/2004GL022318, 2005.

Takahashi, H., Wrasse, C. M., Pancheva, D., Abdu, M. A., Batista, I. S., Lima, L. M., Batista, P. P., Clemesha, B. R., and Shiokawa, K.: Signatures of 3-6 day planetary waves in the equatorial mesosphere and ionosphere, Ann. Geophys., 24, 3343-3350, doi:10.5194/angeo-24-3343-2006, 2006.

Takahashi, H., Wrasse, C. M., Fechine, J., Pancheva, D., Abdu, M. A., Batista, I. S., Lima, L. M., Batista, P. P., Clemesha, B. R., Schuch, N. J., Shiokawa, K., Gobbi, D., Mlynczak, M. G., and Russel, J. M.: Signatures of ultra-fast Kelvin waves in the equatorial middle atmosphere and ionosphere, Geophys. Res. Lett. 34, L11108, doi:10.1029/2007GL029612, 2007.

Takahashi, H., Abdu, M. A., Wrasse, C. M., Fechine, J., Batista, I. S., Pancheva, D., Lima, L. M., Batista, P. P., Clemesha, B. R., Shiokawa, K., Gobbi, D., Mlynczak, M. G., and Russel, J. M.: Possible infuence of ultra-fast Kelvin wave on the equatorial ionosphere evening uplifting, Earth Planets Space, 61, 455-462, 2009.

Tarpley, J. D.: The ionospheric wind dynamo - II - Solar tides, Planet. Space Sci., 18, 1091-1103, 1970.

Teitelbaum, H. and Vial, F.: On tidal variability induced by nonlinear interaction with planetary waves, J. Geophys. Res., 96, 14169-14178, 1991. 